\title{
Survival and Cytological Observations on Early Development of Normal, Hybrid, and Gynogenetic Embryos of Amago Salmon ${ }^{* 1,2}$
}

\author{
Toru Kobayashi ${ }^{\dagger}$ \\ Shiga Prefectural Samegai Trout Farm, Kaminyu, Maihara, Shiga 521, Japan \\ (Received March 13, 1996)
}

The artificial induction of gynogenesis of amago salmon was cytologically confirmed, and the nucleus behavior and the cytological rates were compared at the early stage of development among the following three groups: normal, hybrid between the female amago salmon and the male rainbow trout, and gynogenetic developed group. The first cleavage of hybrid and gynogenetic development was delayed compared with normal development, while that in the gynogens was later than that of the hybrid. The cytological stage at $68 \mathrm{~h} \cdot{ }^{\circ} \mathrm{C}$ in cumulative temperature, which is considered the optimum timing for suppressing the first cleavage of gynogen, was prometaphase. In gynogenetically activated eggs, the lump-shaped body appeared in the metaphase plate. Then, it remained near the cleavage plane in the following cell division, and was considered to be degenerated nuclear materials derived from irradiated sperm, i.e. dense chromatin body (DCB), which could not transform to chromosomes. Therefore, paternally derived genetic materials should disappear during the anaphase and the telophase in the first cleavage of gynogenetic development. Some chromosomes were gradually eliminated in the hybrid development after the first cleavage. This phenomenon was considered a major cause of inviability and the subsequent expression of abnormality during the development of the hybrid.

Key words: cytology, survival, early development, gynogenesis, hybrid, amago salmon, rainbow trout, dense chromatin body

There have been few cytological observations on the early development process of eggs subjected to chromosome manipulation, ${ }^{1-6}$ in spite of a large number of studies on its application for aquaculture. ${ }^{7-9}$ Cytological studies on nuclear behavior during early development and the mechanisms responsible for induced polyploidy are considered important for efficient induction of gynogens and polyploidy. However, in salmonids, there has been no report on cytological observations on the behavior of the nucleus in developing eggs influenced by chromosome manipulations such as induction of gynogenesis and blocking of the meiotic or mitotic process.

In the gynogenetic diploid amago salmon Oncorhynchus rhodurus inseminated with UV irradiated rainbow trout Oncorhynchus mykiss sperm and polyploidized with physical shock treatment, normally developing larvae were regarded as diploid gynogens. ${ }^{10)}$ As the functional sperm of rainbow trout escaped from UV irradiation should be eliminated by inviable hybridization, the resultant embryos were absolutely gynogenetic. ${ }^{10,11)}$ However, the fate of functional and irradiated, heterospecific spermatozoa after insemination has not been cytologically investigated. Cytological observation on the first cleavage is important to standardize the optimum conditions to suppress cell division and to induce the mitotic gynogens, which is major step for the clone production. Some recent opinions ${ }^{5,12,13)}$ vary on the cytologically suitable timing for suppression of the cell division.
The present paper investigates the following three items: 1) the differences on the cytological rates during early development between the amago $q \times$ rainbow trout $\sigma^{7}$ hybrid development and normal amago development; 2) the influence of UV irradiation of rainbow trout sperm on nucleus behavior of the gynogenetic group; and 3) cytological optimum timing of the hydrostatic pressure shock treatment for suppression of the first cleavage.

\section{Materials and Methods}

Eggs and sperm were collected from one pair each of female and male amago salmon, and one male rainbow trout. Approximately 500 eggs of amago salmon were divided into three batches, then each batch (about 150-170 eggs) was inseminated with amago salmon sperm, rainbow trout sperm, or UV-irradiated $\left(2800 \mathrm{erg} / \mathrm{mm}^{2}\right)$ rainbow trout sperm, respectively. The eggs were incubated in a small stainless sieve after the insemination in balanced salt solution (BSS; $0.75 \mathrm{~g} \mathrm{NaCl}, 0.02 \mathrm{~g} \mathrm{KCl}, 0.02 \mathrm{~g}$ $\mathrm{CaCl}_{2} \cdot 2 \mathrm{H}_{2} \mathrm{O}, 0.002 \mathrm{~g} \mathrm{NaHCO}_{3}$, and $100 \mathrm{~m} /$ distilled water) for five minutes, and then kept in circulating fresh water at $12.0^{\circ} \mathrm{C}$.

The survival rates of each experimental group were observed until 50 days after insemination and the formation of embryos was externally observed.

The developing eggs of each group were fixed by Bouin's fixative every $15 \mathrm{~min}$ from 4 to $7 \mathrm{~h}$ after insemina-

\footnotetext{
${ }^{*}$ Study of Biological Characters and the Genetics of Some Traits of Triploid and Gynogenetic Diploid on Salmonid Fishes-V.

*2 Contribution from the Shiga Prefectural Samegai Trout Farm.

$\dagger$ Present address: Shiga Prefectural Fisheries Experimental Station, Hassaka, Hikone, Shiga 522, Japan.
} 
tion (AI). The blastodiscs of the six to eight eggs at each stage were embedded in paraffin, sectioned perpendicular to the polar axis of the egg at $10 \mu \mathrm{m}$ thickness, and stained with Mayer's hematoxylin and eosin.

\section{Results}

\section{Survival in Normal, Hybrid, and Gynogenetic Embryos}

The survival rates of the three groups until 50 days after insemination are shown in Fig. 1. Larvae of the normal group inseminated with amago salmon sperm hatched at 29-42 days AI, and its survival rate was more than $90 \%$ at 50 days AI. In the hybrid group inseminated with rainbow trout sperm, the dead embryos increased gradually from 10 days $\mathrm{AI}$, and no embryo survived when the normally developing individuals hatched. In gynogenetic development activated with UV-irradiated rainbow trout sperm, the survival rates were more than $85 \%$ until just before the hatching stage of the normal group. However, they began to die abruptly from 25 days AI, and all the embryos died before the end of the hatching period of the normal group.

The external appearances of the embryos of the three groups at 18 days AI are shown in Fig. 2. In the normal embryos, formation of somites and differentiation of visceral organs were observed (Fig. 2A). Optic vesicles developed and pigmentation also began. In the hybrid embryos, formation of somites was extremely incomplete, and optic vesicles were not formed (Fig. 2B). In the gynogenetically induced embryos, notochord on the posterior region of the head was undifferentiated, and the optic vesicles were less developed than those of normal embryos both in size and pigmentation. The caudal portion was also undeveloped (Fig. 2C), but the external appearance was better than that of the hybrids and the hematopoietic organ was already differentiated at this stage.

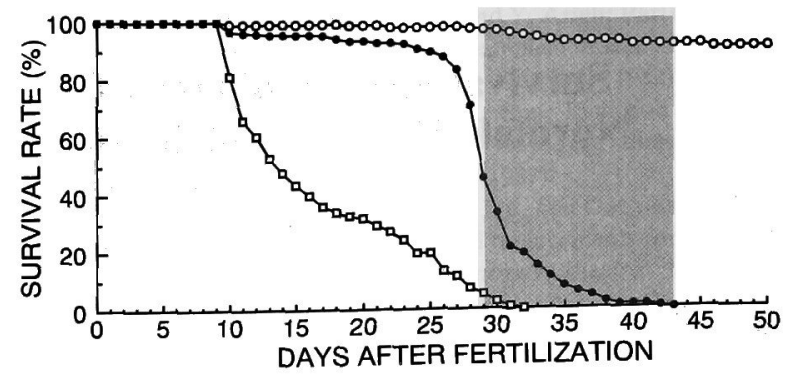

Fig. 1. Survival curves of the normal, gynogenetic, and hybrid eggs between female amago salmon and male rainbow trout.

$O$, Normal development of amago salmon; $\square$, Hybrid development between female amago salmon and male rainbow trout; $\bullet$, Gynogenetic development of amago salmon using UV-irradiated rainbow trout sperm. The dotted area indicates the period when the normal amago embryos hatched out.

\section{Cytological Stage in Early Development}

The relationships between the time after insemination and the developmental stage are indicated in Table 1.

In the normal embryos, the transition from the prophase to the prometaphase in the first cleavage was observed at $4 \mathrm{~h} 45 \mathrm{~min} \mathrm{AI}$, and the metaphase was observed at between $5 \mathrm{~h} 15 \mathrm{~min}$ and $5 \mathrm{~h} 45 \mathrm{~min}$ AI. Then the anaphase and the telophase were observed during the periods from $5 \mathrm{~h} 45 \mathrm{~min}$ to $6 \mathrm{~h} 30 \mathrm{~min}$ and from $6 \mathrm{~h} 30 \mathrm{~min}$ to $7 \mathrm{~h} \mathrm{AI}$, respectively. The first cleavage was completed by $7 \mathrm{~h} \mathrm{AI}$.

In the hybrid embryos, though the transition to the prometaphase began at $4 \mathrm{~h} 15 \mathrm{~min} \mathrm{AI}$, the metaphase appeared at between $5 \mathrm{~h} 30 \mathrm{~min}$ and $6 \mathrm{~h} \mathrm{AI}$. The appearances of the metaphase, anaphase, and telophase were delayed by 15-30 min from the normally developing embryos.

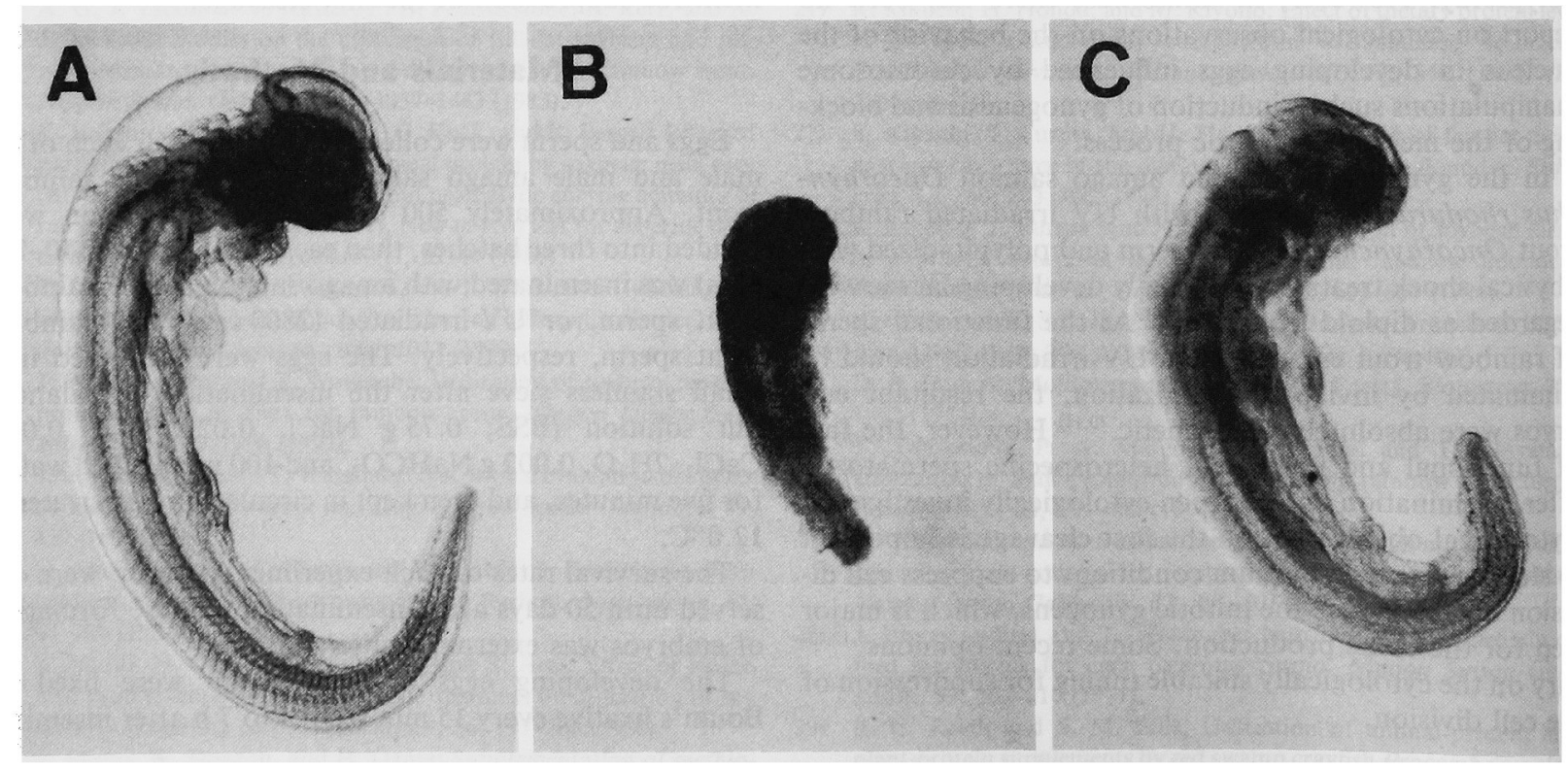

Fig. 2. Embryos at 18 days after fertilization of the normal development of amago salmon (A), hybrid development between female amago salmon and male rainbow trout (B), and gynogenetic haploid of amago salmon inseminated with UV-irradiated rainbow trout sperm (C).

The chorion and the yolk sac were removed to observe the detailed of morphology. 
Table 1. Developmental timetable in normal, hybrid, and gynogenetic eggs after insemination

\begin{tabular}{|c|c|c|c|c|c|c|c|c|}
\hline \multirow{2}{*}{ Group } & \multirow{2}{*}{$\begin{array}{l}\text { Time after } \\
\text { insemination }\end{array}$} & \multicolumn{5}{|c|}{ 1st Cell Div. } & \multicolumn{2}{|c|}{ 2nd Div. } \\
\hline & & $\mathbf{P}$ & PM & $\mathbf{M}$ & A & $\mathrm{T}$ & $\mathrm{P}$ & PM \\
\hline \multirow[t]{13}{*}{ Normal } & $4: 00$ & 6 & & & & & & \\
\hline & $4: 15$ & 6 & & & & & & \\
\hline & $4: 30$ & 5 & & & & & & \\
\hline & $4: 45$ & 1 & 5 & & & & & \\
\hline & $5: 00$ & & 6 & & & & & \\
\hline & $5: 15$ & & & 5 & & & & \\
\hline & $5: 30$ & & & 6 & & & & \\
\hline & $5: 45$ & & & 3 & 2 & & & \\
\hline & $6: 00$ & & & & 5 & & & \\
\hline & $6: 15$ & & & & 5 & & & \\
\hline & $6: 30$ & & & & 5 & 3 & & \\
\hline & $6: 45$ & & & & & 4 & 1 & \\
\hline & $7: 00$ & & & & & 5 & 1 & \\
\hline \multirow[t]{13}{*}{ Hybrid } & $4: 00$ & 4 & & & & & & \\
\hline & $4: 15$ & 4 & 1 & & & & & \\
\hline & $4: 30$ & 2 & 2 & & & & & \\
\hline & $4: 45$ & 2 & 3 & & & & & \\
\hline & $5: 00$ & & 5 & & & & & \\
\hline & $5: 15$ & & 5 & & & & & \\
\hline & $5: 30$ & & 1 & 2 & & & & \\
\hline & $5: 45$ & & & 4 & & & & \\
\hline & $6: 00$ & & & 4 & 1 & & & \\
\hline & $6: 15$ & & & & 5 & & & \\
\hline & $6: 30$ & & & & 5 & 1 & & \\
\hline & $6: 45$ & & & & 4 & 4 & & \\
\hline & $7: 00$ & & & & & 5 & & \\
\hline \multirow[t]{13}{*}{ Gynogenetic } & 4:00 & 4 & & & & & & \\
\hline & $4: 15$ & 4 & & & & & & \\
\hline & $4: 30$ & 4 & & & & & & \\
\hline & $4: 45$ & 5 & & & & & & \\
\hline & $5: 00$ & 4 & & & & & & \\
\hline & $5: 15$ & 1 & & & & & & \\
\hline & $5: 30$ & 1 & 3 & & & & & \\
\hline & $5: 45$ & & 4 & & & & & \\
\hline & $6: 00$ & & 1 & 3 & & & & \\
\hline & $6: 15$ & & & 3 & & & & \\
\hline & $6: 30$ & & & 3 & 1 & & & \\
\hline & $6: 45$ & & & 3 & 1 & & & \\
\hline & $7: 00$ & & & & 5 & & & \\
\hline
\end{tabular}

The eggs were incubated at $12.0^{\circ} \mathrm{C}$.

P, prophase; PM, prometaphase; M, metaphase; A, anaphase; T, telophase.

In the gynogenetic development, transition to the prometaphase occurred from $5 \mathrm{~h} 30 \mathrm{~min}$ to $6 \mathrm{~h} \mathrm{AI,} \mathrm{45-60}$ min later than that of the normal development. The metaphase was noted from $6 \mathrm{~h}$ to $6 \mathrm{~h} 45 \mathrm{~min}$, and the anaphase from $6 \mathrm{~h} 30 \mathrm{~min}$ to $7 \mathrm{~h}$. Thus, the first cleavage of the gynogens did not finish before $7 \mathrm{~h} \mathrm{AI}$. The progress of cell division after the metaphase was 30 min slower than that of hybrids, and 45-60 min slower than that of normal embryos.

\section{The First Cleavage among the Three Types of Embryos}

In the normal development, both male and female pronuclei conjugated each other and then started to swell, fuse, and form the chromosomes. The chromosomes were conformed in a row on the equatorial plate at the metaphase. In the anaphase, each chromosome was divid-

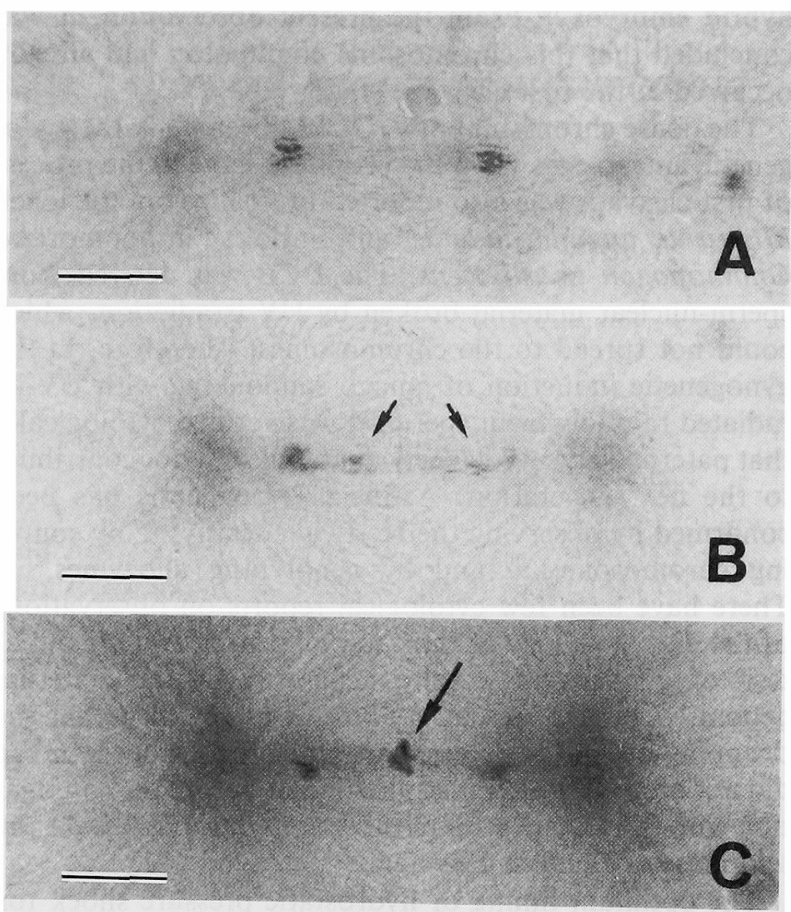

Fig. 3. Cytological microphotographs showing anaphase at the first cleavage in amago salmon eggs.

A, Normal development of amago salmon; B, Hybrid development between female amago salmon and male rainbow trout. Arrow indicate the lagging chromosomes; $\mathrm{C}$, gynogenetic development of amago salmon inseminated with UV-irradiated rainbow trout sperm. Arrow indicates the dense chromatin body. Horizontal bars indicate $5 \mu \mathrm{m}$.

ed into two sister chromatids, drawn by both polars, and then formed two nuclei (Fig. 3A). In contrast, in the hybrid development, the row of chromosomes on the metaphase plate was thicker than in normal development. At the anaphase stage, there were disorders in the chromosome behavior towed by spindle fibers. Some lagging chromosomes were observed (Fig. 3B). In the prometaphase of the first cleavage in gynogenetic development, one pronucleus (probably male pronucleus) was condensed without swelling in the stage when both pronuclei were swelled and fused in the normal process. It never transformed to chromosomes, but became a lump-shaped body, i.e. dense chromatin body (DCB), which was lightly stained with acidic dyes. This DCB was left alone between chromosome groups drawn by both polars on the equatorial plate at the anaphase (Fig. 3C).

\section{Discussion}

Cytological observation on the first cleavage of the hybrid embryos showed that some chromosomes lagged in the process of cell division. A decrease of chromosomes from the theoretical intermediate number has been reported in other inviable hybrids. ${ }^{14,15)}$ Aneuploidy caused by chromosome elimination is considered a major cause of abnormal development and inviability of the amago-rainbow 
hybrid embryos. ${ }^{16)}$ From the present observation, it was concluded that this chromosome elimination had already occurred at the first cleavage stage.

The dense chromatin body (DCB) observed in the gynogenetic amago eggs from the prophase stage in the process of first cleavage was also reported by $\mathrm{Oshiro}^{4)}$ in the loach Misgurnus anguillicaudatus, and Fujioka ${ }^{6}$ in honmoroko Gnathopogon caerulescens. The DCB was derived from sperm-nuclear material broken by UV irradiation, which could not spread to the chromosomes. Therefore, in the gynogenetic induction of amago salmon egg with UV-irradiated rainbow trout sperm, it was verified cytologically that paternally derived genetic materials did not contribute to the next generation. Artificial gynogenesis has been confirmed by observing the Hertwig effect, ${ }^{5,17-19)}$ by counting chromosomes, ${ }^{20)}$ and by genotyping allozymes. ${ }^{21,22)}$ There have been few cytological reports on observations of the disappearance of the paternal genom and the initiation of gynogenetic development only by the maternal genom. ${ }^{4,5)}$ In the present study, it was revealed that the dropping-out of the paternal genom in the gynogenetic egg did not occur just after insemination or before the conjugation with the female pronucleus, but in the anaphase to the telophase of the first cleavage.

The optimum timing of hydrostatic pressure shock for suppressing the first cleavage in the gynogenetic amago eggs was reported to be $68^{\circ} \mathrm{C}$ in cumulative temperature in a previous paper. ${ }^{10)}$ As the eggs were maintained at $12.0^{\circ} \mathrm{C}$ in the present experiment, the optimum $68^{\circ} \mathrm{C}$ in cumulative temperature was comparable to $5 \mathrm{~h} 40 \mathrm{~min}$ after insemination. This time zone was cytologically identified as the prometaphase. Therefore, the prometaphase was concluded as the cytologically optimum timing for the hydrostatic pressure treatment to block the first cleavage. This conclusion is different from that of Purdom et al. ${ }^{12}$ ) and Komen et al. ${ }^{13)}$ who insisted that the cytologically optimum timing for suppressing the first cleavage was the metaphase, but Nagoya et al. ${ }^{\text {s) }}$ reported the same finding. Thus, the author suggests that the cytologically optimum timing for the suppression of the cleavage is the prometaphase.

Acknowledgments The author wishes to express gratitude to Dr. K. Arai, Faculty of Applied Biological Science, Hiroshima University, for his critical reading of the manuscript. This study was supported by a grant-in-aid from the Ministry of Agriculture, Forestry, and Fisheries of Japan.

\section{References}

1) S. Makino and Y. Ozima: Formation of the diploid egg nucleus due to suppression of the second maturation division, induced by refrigeration of fertilized eggs of the carp, Cyprinus carpio. Cytologia, 13, 55-60 (1943)

2) D. D. Romashov, and V. N. Beljaeva : Increased yield of diploid gynogenetic loach larvae (Misgurnus fossilis $\mathrm{L}$.) induced by temperature shock. Tsitologiia, 7, 607-615 (1965).
3) Y. Ojima and S. Makino : Triploidy induced by cold shock in fertilized eggs of the carp. Proc. Jpn. Acad., 54B, 359-362 (1978).

4) T. Oshiro: Cytological studies on diploid gynogenesis induced in the loach Misgurnus anguillicaudatus, Nippon Suisan Gakkaishi, 53, 933-939 (1987).

5) H. Nagoya, T. Kimoto, and H. Onozato: Diploid gynogenesis induced by suppression of the second or third cleavage in the gold fish, Carassius auratus. Bull. Natl. Res, Inst. Aquaculture, 18, 1-6 (1990).

6) Y. Fujioka: Induction of gynogenetic diploids and cytological studies in honmoroko Gnathopogon caerulescens. Nippon Suisan Gakkaishi, 59, 493-500 (1993).

7) G. H. Thorgaard: Chromosome set manipulation and sex control in fish, in "Fish Physiology" (ed. by W. S. Hoar, D. J. Randall, and E. M. Donaldson), Vol. 9, Academic Press, New York, 1983, pp. $405-434$.

8) C. E. Purdom: Chromosome engineering, Genetics and fish breeding, Fish and fisheries series 8, Chapman and Hall, London, 1993, pp. 204-221.

9) K. Fujino: Details on studies and developments of chromosome manipulation technique, in "Chromosome Manipulation and its Application for Aquaculture" (ed. by R. Suzuki), Suisangaku Series Vol. 75, Koseisha-koseikaku, Tokyo, 1989, pp. 9-20 (in Japanese).

10) T. Kobayashi, A. Ide, T. Hiasa, S. Fushiki, and K. Ueno: Production of cloned amago salmon Oncorhynchus rhodurus. Fisheries Sci., 60, 275-281 (1994).

11) R. Suzuki and Y. Fukuda: Survival potential of $F_{1}$ hybrids among salmonid fishes. Bull. Freshwater Fish. Res. Lab., 21, 69-83 (1971).

12) C.E. Purdom, D. Thompson, and Y. D. Lou : Genetic engineering in rainbow trout, Salmo gairdneri Richardson, by the suppression of meiotic and mitotic metaphase. J. Fish Biol. 27, 73-79 (1985).

13) J. Komen, G. Bongers, C. J. J. Richter, W. B. Van Muiswinkel, and E. A. Huisman: Gynogenesis in common carp (Cyprinus carpio L.) II. The production of homozygous gynogenetic clones and $F_{1}$ hybrids. Aquaculture, 92, 127-142 (1991).

14) K. Arai: Developmental genetic studies on salmonids: morphogenesis, isozyme phenotypes and chromosomes in hybrid embryos. Mem. Fac. Fish. Hokkaido Univ., 31, 1-94 (1984).

15) J. Goodier, H-F. Ma, and F. Yamazaki : Chromosome fragmentation and loss in two salmonid hybrids. Bull. Fac. Fish. Hokkaido Univ., 38, 181-184 (1987).

16) K. Arai: Application of the chromosome manipulation technique 8. Allo-polyploidy, in "Chromosome Manipulation and its Application for Aquaculture"' (ed. by R. Suzuki), Suisangaku Series Vol 75, Koseisha-koseikaku, Tokyo, 1989, pp. 82-94 (in Japanese).

17) K. Ijiri and N. Egami: Hertwig effect caused by UV-irradiation of sperm of Oryzias latipes (Teleost) and its photorectivation. Mutation Res., 69, 241-248 (1980).

18) D. Chourrout: Gynogenesis caused by ultraviolet irradiation of salmonid sperm. J. Exp. Zool., 223, 175-181 (1982).

19) H. Onozato and E. Yamaha: Induction of gynogenesis with ultraviolet rays in four species of salmoniformes. Nippon suisan Gak kaishi, 49, 693-699 (1983).

20) D. Chourrout: Induction of gynogenesis, triploidy, and tetraploidy in fish. ISI Atlas of Science (Animal and Plant Sciences), 65-70 (1988).

21) N. Taniguchi, H. Han, and H. Hatanaka : Induction of diploid gynogenetic ayu by UV-irradiated sperm of shishamo smelt with verification by genetic marker. Suisanzoshoku, 39, 41-45 (1991).

22) K. Sugama, N. Taniguchi, S. Seki, H. Nabeshima, and Y. Hasegawa: Gynogenetic diploid production in the red sea bream using UVirradiated sperm of black sea bream and heat shock. Nippon Suisan Gakkaishi, 56, 1427-1433 (1990). 